\title{
LA TEORÍA DEL ESTADO Y DEL PODER EN ANTONIO GRAMSCI: CLAVES PARA DESCIFRAR LA DICOTOMÍA DOMINACIÓN-LIBERACIÓN
}

\author{
Albert Noguera Fernández \\ Universidad de Extremadura
}

\begin{abstract}
Resumen.- Antonio Gramsci murió en la cárcel el 27 de abril de 1937 después de ser detenido en 1926 por la policía fascista de manera ilegal, puesto que era diputado del Partido Comunista Italiano (PCl), y condenado por el Tribunal especial por la defensa del Estado a veinte años de cárcel. Detrás quedaba una vida marcada por la lucha y el compromiso, por delante se levantaba el reto de interpretar una herencia teórica rica y compleja. Este artículo pretende recuperar y presentar el legado teórico de Gramsci, sus aportes a la teoría marxista que durante años, ahogada en el esquematismo y el dogmatismo, se había visto incapaz de entender la estructuración del Estado moderno, así como destacar la validez e importancia de su contribución teórica para la actual teoría del Estado y el poder.
\end{abstract}

Palabras clave.- Hegemonía, cultura, sociedad civil, intelectual orgánico, crisis orgánica, guerra de posiciones.

Abstract.- After being illegally arrested by the fascist police in 1926 -he was an Italian Comunist Party member of parliament- and condemned to twenty years of preason by the Special Tribunal for the State Defense, Antonio Gramsci died in jail on $27^{\text {th }}$ april 1937. Behind his dead remained a life characterized by the commitment and fight, in front of it the challenge to interpret a rich and difficult theoretical legacy. This article try to recover and present the theoretical legacy of Gramsci, his contributions to the marxist theory witch one during a lot of years, drowned in the schematism and dogmatism, it was unable to understand the structure of the modern state, and at the end too, emphasize validity and importance of his theoretical contribution for the now a days State and Power theory.

Keywords.- Hegemony, culture, civil society, organic intellectual, organic crisis, positions war.

\section{Introducción}

Uno de los principales aportes teóricos de Gramsci fue, como veremos a continuación, la caracterización de la dominación en las sociedades modernas, no sólo como un fenómeno económico, sino también y, sobretodo, como un fenómeno subjetivo o cultural, señalando, precisamente, aquel elemento de su teoría, que mantiene mayor actualidad: su interpretación de la cultura como dimensión esencial de estructuración y desarrollo de la dominación en las sociedades estatales modernas.

Sobre el concepto de cultura se ha escrito desde muchas disciplinas, la ciencia política, la psicología social (ej. Kuper 1999; Ratner 2000; Morris y Fu 2000). 
Ahora bien, partiendo de la antropología, podemos definir la cultura como un sistema vivo generado por agentes colectivos socialmente definidos que en unas precisas coordenadas socio-históricas y físicas, dan lugar a producciones materiales, simbólicas e ideacionales de todo tipo, a la vez que son constituidos por ellas.

Dichas producciones generan el sentido de mismisidad (identidad) de las distintas colectividades humanas. $Y$ esa, permite a los agentes sentirse provenientes y reproductores de sí mismos, herederos, transmisores y actores de una determinada manera de identificar el mundo y de modificarlo ${ }^{1}$. Permite, en consecuencia, aquello que Bourdieu y Wacquant denominaron "reflexibilidad"2, capacidad de los agentes sociales de pensar su acción y las propias estructuras en que ella se enmarca, capacidad de comprensión de su realidad, y por tanto, capacidad para incidir en ella de forma intencional cuando se produce la amenaza de sustitución de su coherencia interna, tanto cultural como identitaria, por nuevas formas de organización socio-política más acorde a los intereses de sectores dominantes (dicotomía dominación/liberación).

Lo que Gramsci retoma es el valor de los hechos culturales como conformadores del hombre en la creación de su propia historia.

De acuerdo con todo esto, la tesis que se defiende en este trabajo es que ante el proceso "esencialización" del concepto de cultura que, en nuestras sociedades, se ha producido con la mundialización (la cultura se ha convertido en una esencia fija o muerta, desconectada de los procesos económicos y socio-políticos, a la que, independientemente de su vida diaria, los ciudadanos se adaptan o amoldan determinados días al año para sentirse más mexicanos, españoles o japones -folklore-) y, en consecuencia, ante el proceso de desactivación del concepto de cultura como válido para entender (y actuar frente a) la globalización capitalista como un proceso de subordinación de las diversas culturas ante la cultura de la fracción social dominante (dominación), la recuperación del legado teórico y de la concepción ampliada de cultura de Antonio Gramsci se presenta, en la actualidad, como un factor imprescindible para los sujetos subalternos (individuos y pueblos) a la hora de construir los términos y estructuración de la liberación (comprensión-acción). La dominación es un fenómeno cultural y sólo comprendiendo el concepto de cultura en toda su amplitud, sus mecanismos de funcionamiento y su fenomenología, se puede llegar a entender los procesos de dominación.

Nos detendremos en los próximos puntos, en el análisis que Gramsci hizo del Estado y del poder o hegemonía, en el tratamiento de los cuales el autor hace

\footnotetext{
${ }^{1}$ Esta definición de cultura e identidad ha sido tomada de PIQUERAS, A. La identidad. En DE LA CRUZ, I. (coord.). Introducción a la antropología para la intervención social. Ed. Tirant lo Blanch. Valencia. 2002.

${ }^{2}$ Véase BOURDIEU, P. y WACQUANT, L. Respuestas. Por una antropología reflexiva. Ed. Grijalbo. México. 1995
} 
constantemente referencia a la cultura como dimensión básica para la creación de situaciones de consenso o subversión.

\section{El Estado en la modernidad: poder y autoridad}

Existen dos elementos absolutamente necesarios para la existencia y reproducción de un Estado: el poder y la autoridad.

Por poder entendemos la capacidad o la fuerza de hacer alguna cosa. El poder es en el "nosotros" -en un individuo, un Estado, etc.- en relación con el "vosotros", sobre los que ejercemos nuestro poder. Poder equivaldría pues, a coerción.

Por autoridad entendemos, tal y como define Max Weber en Economía y Sociedad (1922), aquello que, al contrario del poder, me es dado, reconocido, conferido por otros. A alguien se le confiere autoridad porque inspira respeto y confianza. Podríamos entonces traducir la autoridad como persuasión. ${ }^{3}$

Consecuentemente, estos se conforman como los dos elementos necesarios para la salud del Estado. No obstante, la articulación de esta fórmula coerciónpersuasión se ha expresado de manera distinta a lo largo de la historia.

No es hasta la modernidad que podemos identificar el segundo de los elementos, el elemento consensual, como una categoría asociada al Estado. El análisis teórico del Estado pre-moderno redujo éste a la noción de poder, en este período, la creación de autoridad estatal, la formulación de preceptos y reglas de conducta actuantes como prácticas de subjetivización que generaban las actitudes de cohesión voluntaria del individuo entorno al Estado, era una tarea que corresponde no al Estado sino a la religión. Desde el origen de la primera forma de Estado conocida en occidente, la primera gran monarquía medieval aparecida en la segunda mitad del siglo XII hasta terminado el proceso de revoluciones burguesas, la religión es el factor moralizador de la vida social. Ésta es el principal instrumento de control social. El Estado se identifica sólo a una simple estructura jurídico-política que es complementada, o a la que se le solapa, la acción de sujeción de la religión, garantizándole la eficacia de su dominio y la integración del hombre a su estructura.

Con la explosión revolucionaria mediante la cual la burguesía logró apoderarse de las riendas del poder e instaurar el Estado burgués moderno, se inicia un proceso socio-histórico de secularización o laicización del Estado. Cada vez menos, los individuos interpretan la vida personal y colectiva en base a cosmovisiones religiosas. Desde una perspectiva histórica, la modernidad supone que por primera vez, las explicaciones y legitimaciones religiosas del mundo pierden su plausibilidad para gran parte de la población y, en consecuencia, la legitimidad de lo político deja de pasar por lo trascendente o

\footnotetext{
${ }^{3}$ Véase WEBER, M. Economía y Sociedad. Ed. Fondo de Cultura Económica. México. 1944. V.I. Pág. 221.
} 
religioso. Por lo tanto, el nuevo reto que esta situación plantea al Estado moderno, es la necesidad para su supervivencia, como dice M. Calvo en La teoría de las pasiones y el dominio del hombre. Genealogía de la hermenéutica moderna del control social (1989), de "reconstruir los mecanismos de control social de la religión sin la religión"4.

La función de la religión como mecanismo de control social, deben ser desarrolladas ahora, por un entramado nuevo de las formas del poder en el que se conjuguen, los contenidos de una ética social secularizada y las formas y prácticas de subjetivización, que hagan posible conectar los adentros psicológicos del hombre con los imperativos del orden social ${ }^{5}$. El Estado burgués debe superar su interpretación histórica como mero conjunto de instrumentos de coerción, para pasar a interpretarse a si mismo, también como sistema de instrumentos de producción de liderazgo intelectual y de consenso. Debe pues, expandirse molecularmente, redimensionar su morfología de manera que le permita incorporar junto al elemento Estado-fuerza, una función educadora o de socialización.

Asistimos a una ampliación en la concepción del Estado, los aparatos ideológicos pasan a formar parte, como establecerán Nikos Poulantzas en Fascismo y Dictadura (1970) o Louis Althusser en Ideología y Aparatos Ideológicos de Estado (1970), de los aparatos de Estado. En su nueva significación integral éste abarcará:

1) el elemento de reconocimiento o de legitimidad, que se da cuando los individuos reconocen un orden como legítimo. Este elemento representará en la modernidad, el elemento interno de caracterización del concepto Estado; y, 2) el elemento coacción, que actúan en el nivel de las "garantías" de la legitimidad y de la eficacia del orden estatal. La coactividad aparece ya no como elemento constitutivo, sino como una característica exterior del orden válido;

Tal complementariedad entre las condiciones externas del poder y las formas de subjetivización del mismo, son resumidas en la definición de Estado hecha por D. Grissoni y R. Magiori en su obra Leer a Gramsci (trad. 1974), partiendo como no, de la obra de Gramsci. ${ }^{6}$

${ }^{4}$ CALVO, M. La teoría de las pasiones y el dominio del hombre. Genealogía de la hermenéutica moderna del control social. Ed. Universidad de Zaragoza, Prensas Universitarias. 1989. Pág. 100.

${ }^{5}$ Idem. Pág. 117.

${ }^{6}$ Grissoni y Magiori definen el Estado de la siguiente manera: "El Estado es el conjunto de organismos por medio de los cuales se ejerce la hegemonía y la coerción de la clase dirigente sobre las clases subalternas, no con la mera intención de preservar, defender y consolidar sus intereses económico-políticos, sino también para elaborar una acción educativa de conformidad del conjunto del cuerpo social, de manera que los objetivos e intereses de la clase dominante aparezcan como datos y valores universales". (GRISSONI, D. y MAGIORI, R. Leer a Gramsci. Ed. Zero. Madrid. 1974. Pág. 167). 
Los grandes aportes del autor italiano a la teoría marxista de la época que, hundida en el economicismo dogmático se mostraba totalmente incapaz de entender el Estado en toda su complejidad, giran, como es sabido, entorno a la dictadura de clase y su contenido de "hegemonía", es decir, en el sentido del "consenso" con el que llega a contar la clase en el poder. Mediante sus escritos, Gramsci planteó un conjunto de ideas inéditas para la teoría del Estado y el poder, marxista y no marxista, existente hasta entonces y que, revolucionaron este campo de estudio. Ideas que prefiguran muchas de las que, varios decenios después de la redacción de Los Cuadernos, serían presentadas -como resultado independiente de sus propias reflexiones- por Michel Foucault ${ }^{7}$. Detengámonos pero ahora en la teoría de Gramsci.

\section{La obra de Gramsci. Dificultades para leerla}

Existen varias razones que hacen de la obra de Gramsci una obra de difícil lectura. Algunas de éstas son:

- Gramsci había sido fundador del PCl y durante la dictadura de Mussolini, era uno de sus máximos dirigentes, hecho que lo llevó a la cárcel. Es en condiciones de encarcelamiento (1926-1937) y, por tanto, de censura -a Gramsci le entregaban un cuaderno, cuando lo terminaba se lo revisaban y de pasar la censura le entregaban otro para que continuara-, que escribe la mayor parte de su obra, Los cuadernos de la cárcel. Por este motivo, tiene que usar códigos en su escritura, utilizando términos que encubrieran el tratamiento de temas que pudieran provocar se le retirara el privilegio de poder escribir, para referirse a Marx y Engels habla "del uno y del otro", para hacerlo de Lenin dice "llici", para decir filosofía marxista dice "filosofía de la praxis", etc.;

- El carácter desordenado, fragmentado y en ocasiones inconcluso de sus escritos. Gramsci escribía sobre un tema, de repente lo hacía sobre otro para

\footnotetext{
${ }^{7}$ Al igual que Gramsci, Foucault alertó del carácter difuso de las redes de relaciones que afianzan la dominación, e insistió que el poder de la clase dominante no se apoya sólo, ni esencialmente, en el control de las estructuras públicas institucionalizadas (Estado), sino en su capacidad de regular los procesos de producción cultural. La tesis fundamental de Foucault es que no existe una instancia puntual de poder. El estatuto ontológico del poder no es el de un "ente-objeto" concentrado en las instituciones públicas y desde donde se controla todo, sino que el poder es una compleja red de relaciones que se expande transversalmente en la sociedad a través de todo el conjunto de organismos e instituciones sociales (micropoderes).

Si bien Foucault coincidia con Gramsci en que el poder se basa en la producción de subjetividad o cultura, la gran crítica que autores como Perry Anderson, Anthony Giddens, Alain Tourain o Jürgen Haberlas, hicieron a la obra de Foucault, fue su excesiva "ontologización" del poder. El haber absolutizado tanto la capacidad abarcadora y el efecto homogeneizador del poder que lo convertían en algo de lo que era imposible escapar (las estructuras sociales predeterminan la actividad y el pensar de los sujetos, al margen de su voluntad y sin que este pueda hacer nada. El sujeto como "idiota cultural") y, por tanto, en su teoría no había espacio para la resistencia y la subversión. (Véase FOUCAULT, M. Vigilar y castigar. Ed. Siglo XXI. México. 1986; TOURAIN, A. Crítica a la modernidad. Ed. Temas de hoy. Madrid. 1993; GIDDENS, A. Política y sociología en Max Weber. Ed. Alianza. Madrid. 1995).
} 
volver después al primero y así sucesivamente, llegando a encontrar incluso fragmentos que se contradicen abiertamente;

- La dificultad para encontrar su obra. Después de la muerte de Gramsci, su cuñada consiguió llevarse los originales a la Unión Soviética, donde tuvieron que esperar hasta el final de la II Guerra Mundial para poder pensarse en su publicación. En 1948 por primera vez, el PCl publica unos volúmenes agrupando la obra de Gramsci por temáticas, ésta no obstante, no sigue el orden cronológico que le dio el autor. Más tarde en 1975 se publicó la famosa Edición crítica que son los cuadernos publicados tal y como los escribió el autor. La publicación a otros idiomas de esta obra también ha tenido una historia complicada, hasta mediados de los 80 no se dispuso de una traducción no ya completa, sino confiable, de los cuadernos de cárcel en alemán. En español, empiezan a aparecer a finales de los 50 en Argentina algunos textos traducidos, pero no es hasta el año 2000, que la editorial Era, de México, ha consiguió completar la edición integra y crítica de los Cuadernos; y,

- La bibliografía pasiva. Durante muchos años Gramsci ha sido silenciado por el propio marxismo dogmático oficial o soviético. La instrumentalización que a lo largo de su historia, ha hecho el $\mathrm{PCl}$ y otros intelectuales de la obra de Gramsci, para justificar públicamente su apuesta por la moderación y el reformismo (eurocomunismo, "el compromiso histórico", etc.) ${ }^{8}$, llevó al rechazo de Gramsci por parte del resto de los Partidos Comunistas y a la eliminación de este en los estudios sobre marxismo. En la República Democrática Alemana, en la década del 80, se incluyó el estudio de Gramsci para los estudiantes de la carrera de filosofía en algunas universidades, pero en ninguno de los países del campo socialista europeo se utilizó su obra en la enseñanza de la filosofía marxista a los estudiantes de otras carreras. En Cuba, durante la década de 1960 en las selecciones de lecturas para los estudiantes publicadas por el Departamento de Filosofía de la Universidad de La Habana se incluyeron fragmentos de El materialismo histórico y la filosofía de Benedetto Croce y Gramsci estaba incluido en la enseñanza de la filosofía en todas las carreras universitarias, a partir de 1971 pero, con la apropiación de toda la esfera académica y de la enseñanza cubana por parte del marxismo dogmático, este desaparece de los programas y no es recuperado hasta finales de los $80 .^{9}$

\footnotetext{
${ }^{8}$ Uno de las principales autores, que difundió una interpretación instrumentalizada y errónea de Gramsci fue Norberto Bobbio. En el Congreso sobre Gramsci celebrado en Cagliari en 1967, Bobbio presentó la ponencia "Gramsci y la concepción de la Sociedad Civil", en la que se despoja todo el pensamiento gramsciano de su contenido revolucionario. (Véase BOBBIO, N. Gramsci y la concepción de la sociedad civil. Ed. Avante. Barcelona. 1977).

${ }^{9}$ Sobre la recepción de Gramsci en Cuba véase VV.AA. Hablar de Gramsci. Ed. Centro de Investigación de la Cultura Cubana Juan Marinello / Cátedra de Estudios Antonio Gramsci. La Habana. 2003. Pág. 75-171.
} 


\section{El concepto de hegemonía y el lugar de su constitución: la sociedad civil}

El concepto de Hegemonía fue usado por primera vez en 1919 por Lenin y Plejanov en su sentido etimológico de "conducir" o "ser guía", para indicar la misión del proletariado como dirigente del resto de las clases sociales. Esta concepción hay que contextualizarla en el enfrentamiento que durante la llamada fase democrático-burguesa de la Revolución soviética mantienen los sectores bolchevique y menchevique respeto el papel que había de jugar el proletariado en el interior de la alianza de la clases que había hecho triunfar la revolución. El concepto de Hegemonía usado primeramente por Lenin y Plejanov surge pues, para referirse al papel central o "hegemónico" que juega una clase social en una alianza de clases.

La elaboración posterior efectuada por Gramsci es, sin embargo, la que ha terminado imponiéndose en las Ciencias Sociales como una nueva visión del poder. El desarrollo del concepto de Hegemonía que Gramsci realiza, movido por un interés político-práctico de entender los mecanismos de conformación y consolidación de la dominación y la estrategia a seguir por la revolución para subvertirlos, nace de la observación del fascismo en la Italia y la Europa de su época. La pregunta: ¿Cómo es posible que el fascismo pueda asimilar y obtener el apoyo voluntario de las masas, incluida la clase obrera?; y el análisis de esta causa: uso de mecanismos complejos de movilización ideológica, el constituirse como un movimiento de masas, la utilización del poder carismático, la estetización de la política (la política como expresión estética), la implementación de políticas sociales (aumento salarios, construcción de viviendas, etc.), el corporativismo o crítica al parlamentarismo liberal por su incapacidad de representar a las masas, el recurso a la irracionalidad y el repudio a la racionalidad, etc.; es lo que lleva al autor italiano a empezar a reflexionar sobre el poder y a plantearse aquello político, no como un fenómeno puramente económico de acuerdo con lo que concebía el marxismo oficial de la III Internacional, representado por Bujarin, el cual pensaba que la crisis económica en la devastada Europa de posguerra llevaría a la crisis política del capitalismo, sino como alguna cosa que se mueve en el campo de lo espiritual, en la esfera de la gnoseología. La dominación no es algo objetivo y separado del hombre, sino también algo que existe en el hombre, los hombres "obedecen" o "desobedecen" impulsados por un sentido de moralidad, por creer que unas normas son "buenas-malas", "justas-injustas".

Aunque no aparece en la obra de Gramsci una definición formal del concepto hegemonía, puede entretejerse de su conjunto una definición de lo que el autor entiende por ello. Uno de los trazos característicos de las sociedades capitalistas, dice, es la existencia en períodos de normalidad (cuando no se agudiza la amenaza o el estallido de algún tipo de crisis) de un consenso generalizado -activo o pasivo- por parte de las diferentes clases sociales hacia la dirección que otra clase ejerce sobre el conjunto de la formación social. La existencia de este consenso generalizado, obtenido gracias a un determinado control-dirección de índole ideológica ejercida por una clase, significa que esa clase es hegemónica. 
Ahora bien, tal dominación de carácter consensualista, el control-dirección de índole ideológica, este "hacer hacer" -conseguir que los individuos produzcan unas y no otras conductas de manera totalmente voluntaria-, la clase hegemónica consigue llevarla a cabo no por la capacidad de convicción de su discurso, de su fraseología, por tener capacidad de pronunciar un conjunto de palabras que crean el frenesí en las masas, sino porque es capaz de estructurar la construcción ideológica de la sociedad alrededor de un sistema cultural. La Hegemonía para Gramsci, como afirmábamos al inicio, es una producción cultural.

La construcción de la dominación capitalista, establece, tiene sus fundamentos en un proceso histórico de deconstrucción-construcción de lo social, de creación de un sistema de relaciones sociales, legitimador y reproductor de la dominación burguesa, que aparece ante nosotros como natural y necesario cuando en realidad no es más que cultural y artificial. Como escribió Georg Jellinek en su Teoría General del Estado (1900): "el origen de la creencia de que existen relaciones normales, procede de una determinada actitud del hombre, psicológicamente condicionada, ante los hechos. El hombre ve lo que constantemente le rodea, lo que sin cesar percibe y sin interrupción ejecuta, no sólo como un hecho, sino también como una norma de juicio, a la que intenta hacer que se conformen $y$ adecuen los hechos heterogéneos y discordantes"10.11 "Una realidad histórica objetiva -dice Eric Weil en Hegel e lo Stato e altri scritti hegeliani (1988)- es necesaria no por sí misma, sino porque el hombre ha creado una esfera de la necesidad"12. Así pues, la construcción de una cotidianidad o realidad de vida cotidiana -relación de las personas entre ellas, con las instituciones y estructuras sociales, la producción simbólica, la naturaleza y el mundo de objetos materiales- donde modos de prodecer ideológicos establecidos por la clase dominante se convierten en modos de proceder lógicos de y para todos (la repetebilidad deviene normalidad), es el elemento básico para la construcción de la Hegemonía política. En este sentido Gramsci define el "sentido común", que describe como la "conciencia cotidiana", como la "filosofía de los no filósofos", como un instrumento de

10 JELLINEK, G. Teoría General del Estado. Ed. Librería General de Victoriano Suarez. Madrid. 1914. T.I. Pág. 428.

${ }^{11}$ Georg Jellinek conjuntamente con Eugene Ehrlich fueron los máximos representantes de la llamada concepción psicologista del Derecho, la cual afirmaba que los hombres obedecen o desobedecen las normas impulsados o motivados por un sentido de moralidad, por creer que estas son "buenas" o "malas", "justas" o "injustas" (idea expresada ya previamente en 1984 por Rudolf Bierling en Juristische Prinzipienlehre (véase BIERLING, E.R. Juristische Prinzipienlehre. T.I. friburgo de Besgovia/Leipzig. 1894. Citado por ALEXY, R. Concepto y validez del Derecho. Ed. Gedisa. Barcelona. 1994. Pág. 23). Pero ¿quien o qué determina este sentido de moralidad?, ¿qué determina lo que los hombres creen como bueno o malo?. Tanto el propio Jellinek, como Ehrlich, afirman que tal sentido de moralidad es modelado y determinado, en gran parte, no por principios de justicia absolutos y universales como establece la interpretación iusnaturalista, sino por el poder del hábito, por lo que llaman, la fuerza normativa de lo real. (Véase JELLINEK, G. Ob. Cit. y EHRLICH, E. Metodología de la ciencia del derecho.Ed. Ariel. Barcelona. 1980).

${ }^{12}$ WEIL, E. Hegel e lo Stato e altri scritti hegeliani. Ed. Guerini. Milán. 1988. pág. 258-259. 
dominación de clase. "Lo que hace que el poder se sostenga, que sea aceptado, -dirá Foucault años más tarde- es sencillamente que no pesa sólo como potencia que dice no, sino que cala de hecho, produce cosas, induce placer, forma saber, produce discursos; hay que considerarlo como una red productiva que pasa a través de todo el cuerpo social en lugar de cómo una instancia negativa que tiene por función reprimir" ${ }^{13}$.

Es por ello que Gramsci se refiere a la necesidad para toda clase social que quiera tomar el poder e instaurar un orden favorable a sus intereses, de promover primero, una transición o adaptación de la realidad social hacía su ideología-cultura: "La supremacia de un grupo social se manifiesta de dos modos, como dominio y como dirección intelectual y moral. Un grupo social es dominante respecto de los grupos adversarios que tiende a liquidar o a someter incluso con la fuerza armada, y es dirigente de los grupos afines y aliados. Un grupo social puede y hasta tiene que ser dirigente ya antes de conquistar el poder gubernativo (esta es una de las condiciones principales para la conquista del poder); luego, cuando ejerce el poder y aunque lo tenga firmemente en las manos, se hace dominante pero tiene que seguir siendo también dirigente. (...) debe haber una actividad hegemónica incluso antes de llegar al poder, no se tiene que contar sólo con la fuerza material que da el poder para ejercer una dirección eficaz"14. A este proceso previo de transformación de las relaciones sociales por parte de una clase, es lo que Gramsci, tomando un concepto que había sido utilizado por Vicenzo Couco (1770-1823) para referirse a la revolución napolitana de 1799, Ilama una "revolución pasiva" o "revolución sin revolución".

Sobre esta cuestión, Max Weber en La ética protestante y el espíritu del capitalismo (1905), explicó de forma brillante como la expansión durante los siglos XVI y XVII del protestantismo ascético de impronta calvinista-puritana, el cual anclaba su ética en la "teoría de la predestinación" ${ }^{15}$, permitió a la burguesía -el mapa de consolidación de la reforma viene a coincidir con las áreas del mundo francogermano y flamenco donde existe mayor desarrollo comercial- empezar a desarrollar en la población, una "mentalidad capitalista" ya antes de las revoluciones con las que más tarde conquistarían el poder. La

${ }^{13}$ FOUCAULT, M. Un diálogo sobre el poder y otras conversaciones. Ed. Tecnos. Madrid. 1981. Pág. 137.

${ }^{14}$ GRAMSCI, A. Antología. Ed. Siglo XXI.México. 1977. Pág. 486.

${ }^{15}$ Ésta teoría parte de los siguientes principios: Dios ha decidido desde la eternidad condenar a una parte de la humanidad y salvar la otra, sin que los hombres puedan hacer nada para alterar este designio divino. A la cuestión que este axioma genera inmediatamente en cada uno de los creyente: ¿soy yo un elegido? ¿cómo puedo estar seguro de esta elección?, los calvinistas predican a sus creyentes que tienen la obligación de sentirse elegidos y rechazar cualquier duda como "tentación del demonio", pues si faltaba esa seguridad era señal de una fe insuficiente. La manera de estar seguros de su elección es un trabajo profesional permanente e infatigable, solo llevando una vida orientada sistemáticamente al trabajo profesional como medio para la glorificación de Dios, se puede tener la certeza subjetiva de ser un elegido. El trabajo sin descanso, no sirve para "conquistar" la salvación, pero sí para liberar al creyente del miedo acerca de su salvación. 
Reforma protestante, mediante su teoría de la predestinación, desarrolló en los creyentes calvinistas un modo de vida caracterizado por la sistematización y por la organización completa de la vida entorno al trabajo. Si antes, el trabajo era un medio, el hombre trabajaba para conseguir el dinero necesario con que satisfacer sus necesidades materiales y en caso de disponer de alguna riqueza evitaba trabajar, ahora el trabajo se convierte en un fin en su mismo (surge la idea de "profesión"), el hombre queda referido a la idea de trabajar y ganar dinero como el objetivo de su vida. Se crea el "hombre económico" moderno ${ }^{16}$. En palabras de Gramsci: "toda revolución ha sido precedida por un intenso trabajo de crítica, de penetración cultural, de permeación de ideas" ${ }^{17}$.

En resumen, cuando una clase social o alianza de clases consigue el control a la vez, de los medios de producción (infraestructura económica) y el control de la dirección ideológica de la sociedad (superestructura político-ideológica), Gramsci dice que esa clase crea un Bloque Histórico: "la estructura y las superestructuras forman un bloque histórico, o sea, que el conjunto complejo, contradictorio y discorde de las superestructuras es el reflejo de las relaciones sociales de producción" ${ }^{18}$, y por tanto es hegemónica, como dice M.A. Macciocchi: "estos dos conceptos -hegemonía y bloque histórico- son inseparables puesto que, según Gramsci, es en el interior de un bloque histórico donde se realiza una hegemonía determinada"19.

Como he señalado anteriormente, para que una clase se haga con el controldirección de índole ideológica, ésta ha de conseguir estructurar la construcción ideológica de la sociedad alrededor de un sistema cultural o de relaciones sociales, de ahí la importancia que en Gramsci tendrá el concepto de "Sociedad Civil".

Sobre el concepto de Sociedad Civil se desarrolla gran parte del sistema conceptual gramsciano. La Sociedad Civil, dice Gramsci, es el espacio de la ideología, el marco donde se produce la Hegemonía, no entiende por Sociedad Civil pero, ni en el sentido actual (Sociedad Civil como todo aquello que no es Estado o como espacio de libre asociatividad) ni en el sentido que lo hicieron Marx y Engels en La Ideología Alemana (1845-46) (identifican Sociedad Civil con infraestructura económica, pues consideran la primera como el conjunto de las relaciones materiales de los individuos en una etapa a la que corresponde un determinando desarrollo de las fuerzas productivas) ${ }^{20}$, sino como

\footnotetext{
${ }^{16}$ Véase WEBER, M. La ética protestante y el espíritu del capitalismo. Ed. Alianza. Madrid. 2001.

${ }^{17}$ GRAMSCI, A. Antología. Ed. Ciencias Sociales. La Habana. 1973. Pág. 16.

${ }^{18}$ GRAMSCI, A. El materialismo histórico y la filosofía de Benedetto Croce. Ed. Nueva Visión. Buenos Aires. 1971. Pág. 49.

${ }^{19}$ MACCIOCCHI, M.A. Pour Gramsci. Editions du Seuil. Paris. 1974. Pág. 161.

${ }^{20}$ Por tal motivo afirma Norberto Bobbio que el rescate gramsciano del concepto no es lo que le asocia a Marx sino lo que le distancia de él. (BOBBIO, N. Gramsci y la concepción de la Sociedad Civil. 1968. Pág. 149. Citado por ALONSO, A. El contexto de Sociedad Civil en el
} 
"organización social", como institución con unas normas sociales, Sociedad Civil como opuesto a Sociedad Natural o Salvaje. A Gramsci le interesa destacar la Sociedad Civil no como un espacio donde hay determinadas cosas, sino como una organización o sistema de relaciones sociales con unas normas en funcionamiento, englobantes y asimilantes que encarrilan la actividad y el pensar de los sujetos, que los definen y constituyen a todos por igual como miembros de una misma cultura.

En este sentido, Gramsci divide el Estado en dos grandes planos superestructurales: la Sociedad Civil, que constituye el momento de la hegemonía o del consenso, y la Sociedad Política ${ }^{21}$, que constituye el momento de la fuerza, de la coerción y dominación considerada en su sentido estricto y de acuerdo con la concepción tradicional del Estado como máquina para la opresión de una clase sobre las otras. ${ }^{22}$ El Estado es igual a Sociedad Civil más Sociedad Política, que equivale a decir, "Hegemonía revestida de coerción" ${ }^{3}$ o "Hegemonía más dictadura" 24 . Tal división le costo a Gramsci una

debate contemporáneo. En Revista Internacional Marx Ahora. Núm. 2. La Habana. 1996. Pág.122.)

${ }^{21}$ No hay que confundir "dirección política" con "Sociedad Política". La Sociedad Política es en Gramsci el lugar correspondiente a la función de dominio directo, pero la dirección política es un aspecto de la hegemonía y no se identifica con la fuerza. El ejercicio de control-dirección ideológica de una clase sobre las otras, mediante la cual la primera se hace hegemónica, engloba dos tipos de dirección:

- la dirección intelectual-moral: ésta es la dirección ideológica propiamente dicha, entendiendo ideología en tanto hecho cultural, es decir como la unión de una concepción del mundo con unas normas de conducta que se desprenden de ella. Esto es, la elaboración-difusión de la concepción del mundo que, propia de una clase, llega a generalizarse en toda la formación social, extendiéndose hasta tal punto entre las otras clases que éstas llegan a actuar y pensar según los valores y principios inculcados por aquella. De esta manera se legitima todo un sistema de relaciones sociales cristalizado en el Estado y, en consecuencia, se legitima indirectamente al Estado; $y$,

- la dirección política: la constituyen el conjunto de organismos que más tarde han sido llamados Aparato Ideológico del Estado Político o Aparato Ideológico Político, y que engloba en general el aparato de régimen de democracia parlamentaria propio de países occidentales, es decir: parlamento, sufragios, partidos, etc., a través de los cuales se elabora y difunde una concepción que presenta el Estado como algo con carácter universal, como representante del interés general del pueblo-nación, con todo lo cual se legitima directamente al Estado;

En consecuencia, Dirección Política ejercida en la Sociedad Civil, no es igual a dominación política, ejercida en la Sociedad Política.

22 “... Se pueden fijar dos grandes planos superestructurales -dice Gramsci-: el que puede llamarse de la Sociedad Civil, es decir, el conjunto de organismos vulgarmente llamados privados, y el de la Sociedad Política o Estado, que corresponden a la función de hegemonía ejercida por el grupo dominante en toda la sociedad y a la función de dominio directo o de mando que se expresa en el Estado y en el gobierno jurídico". (GRAMSCI, A. Cultura y Literatura. Ed. Península. Barcelona. 1972. Pág. 35).

${ }^{23}$ GRAMSCI, A. Notas sobre Maquiavelo, sobre la política y sobre el Estado Moderno. Ed. Nueva Visión. Buenos Aires. 1972. Pág. 158.

${ }^{24}$ GRAMSCI, A. Passato e Presente. Editori Riuniti. Roma. 1971. Pág. 104. 
dura crítica por parte de Nicos Poulantzas (1936-1979) en Hegemonía y dominación en el estado moderno (trad. 1969). ${ }^{25}$

Ahora bien, en su función de espacio de elaboración-difusión de la ideología, la Sociedad Civil puede abordarse, según Gramsci, desde dos perspectivas:

1) abajo-arriba. Sociedad Civil como "disgregación" del sistema hegemónico (subversión); o,

2) arriba-abajo. Sociedad Civil como "contenido ético" de Estado (dominación). La principal diferencia entre estos dos momentos está en la inexistencia en el primer caso, y existencia en el segundo, de un nexo, en palabras de Gramsci "orgánico", entre Sociedad Civil y Sociedad Política, entre sociedad y Estado. La adhesión de cualquier teoría social de clase a la primera o segunda de estas dos concepciones de Sociedad Civil (dominación-subverción), variará en función de si su posición en la jerarquía social del poder se ubica arriba o abajo.

Como describe Jorge Luis Acanda hace en su libro Sociedad Civil y hegemonía (2002), en el liberalismo temprano del siglo XVII, en un contexto histórico de lucha liberal por el tránsito del feudalismo al capitalismo y, por tanto, desde una posición de oprimidos (abajo), "cuestionando los poderes de las monarquías despóticas y sus pretensiones de sanción divina, el liberalismo pretendío restringir los poderes del Estado y definir una esfera privada especial, independiente de la acción del Estado" ${ }^{26}$, la Sociedad Civil, donde pudiera auto-desarrollarse como clase.

Aquí, ésta era entendida como el espacio donde los individuos propietarios desplegaban su actividad mercantil, como espacio público de intercambio e

${ }^{25}$ La crítica que en este sentido, formuló sobre él, Nicos Poulantzas en Hegemonía y dominación en el Estado moderno, fue, el haber querido restringir el concepto de hegemonía y de distinguir en principio, en las estructuras de dominación y de explotación de la sociedad moderna, entre poder directo de dominación -fuerza y coerción- ejercido por el Estado y el gobierno "jurídico" (o sea por la Sociedad Política, término empleado no el sentido marxista del Estado político sino en el que asume en la ciencia política en general) y poder indirecto de dirección intelectual y moral y de organización-hegemonía, ejercido por la clase hegemónica en la Sociedad Civil por medio del conjunto de las organizaciones habitualmente consideradas como "privadas" (iglesia, enseñanza, instituciones culturales, etc.). Gramsci -dice Poulantzassólo pudo concebir esos dos aspectos del poder como manteniendo relaciones de complementariedad: "el más grande teórico moderno de la filosofía de la praxis -nos dice Gramsci de Lenin- en el terreno de la lucha y la organización política revaluó, en oposición a las diversas tendencias economistas, el frente de la lucha cultural y elaboró la teoría de la hegemonía como complemento de la teoría del Estado-fuerza", pero no como una unidad contradictoria de dirección-violencia, organización-coerción, etc. A pesar de esta crítica de Poulantzas, no cabe duda que si Gramsci se hubiera detenido más en lo jurídico, en congruencia consigo mismo, hubiera reconocido junto al carácter represivo, el carácter positivo o movilizador del Derecho, como dos caras de un mismo fenómeno. (POULANTZAS, N. Hegemonía y dominación en el Estado moderno. Ed. pasado y presente. Córdoba. Argentina. 1969. Pág. 77 y 78$)$.

${ }^{26}$ HELD, D. Modelos de democracia. Ed. Alianza. Madrid. 1991. Pág. 58. 
interacción económica. El desarrollo de tal Sociedad Civil, en estrecha interrelación con las nociones de individuo (entendido como varón propietario) y razón (transfigurada en razón instrumental, como expresión sublimada de las leyes del funcionamiento del mercado), fueron los tres elementos básicos y consustanciales a la revolución efectuada por la burguesía y constituyó una arma fundamental para la disolución de la sociedad feudal y creación de la modernidad.

La concepción liberal-temprana de la Sociedad Civil implicó pues, la "autonomización" de lo social con respecto a lo político y lo estatal ${ }^{27}$, la separación entre Sociedad Civil y Sociedad Política y la constitución de la Sociedad Civil como espacio de disgregación de la hegemonía feudal.

También Marx, y partiendo de esta primera interpretación de la Sociedad Civil, en La guerra civil en Francia (1871), donde aporta ideas de carácter estratégico para los proyectos socialistas ulteriores, señala, particularmente en el capítulo tercero, la Sociedad Civil -ejemplificada mediante la Comuna de París- como el espacio desde donde articular la organización de los trabajadores y el proceso revolucionario enfilado contra la burguesía y el capitalismo. ${ }^{28}$

Por el contrario, esta concepción cambia cuando la Sociedad Civil se analiza desde "arriba". Una vez situada en el poder, la burguesía se esforzó por neutralizar la carga o el contenido originalmente crítico de la Sociedad Civil, y articular el enlace Estado-Sociedad Civil, convirtiendo a ésta en espacio no de rebelión sino de socialización. La nueva concepción de Sociedad Civil como "contenido ético" de Estado va conformandose de manera progresiva.

En contra del planteamiento inicial del liberalismo -Estado no interventor(ruptura individuo-comunidad) Georg W. F. Hegel (1770-1831) planteó la necesidad para conseguir la adhesión de los ciudadanos entorno al Estado, de crear unos valores éticos comunes - Sittlichkeit- (diferencia entre interés público y privado), haciendo que el hombre dejara de concebirse como un simple sujeto individual y se apropiara "en si" del ciudadano abstracto del Estado, que en su calidad de hombre individual devenga también ser genérico. Si bien el aporte de Hegel no rompió todavía la separación entre Sociedad Política y Sociedad Civil, sí fue el primero que concibió estas dos esferas no ya como contrapuestas, sino como profundamente interrelacionadas por nexos de exterioridad.

El proceso de fusión completa entre Sociedad Política y Civil se produce, como describió brillantemente Gramsci, a partir de 1848. La fuerte y creciente

\footnotetext{
${ }^{27}$ Véase ACANDA, J. L. Sociedad Civil y Hegemonía. Ed. Centro de Investigación y Desarrollo de la Cultura Cubana Juan Marinello. La Habana. 2002. Pág. 133-135.

${ }^{28}$ Véase MARX, K. La Guerra Civil en Francia. En MARX, K. y ENGELS, F. Obras escogidas en dos tomos. Ediciones en lenguas extranjeras. Ed. Progreso. Moscú. 1955. T.I. Pág. 539555.
} 
organización de la clase obrera en diversas formas asociativas y sus demandas entorno a los "derechos de ciudadanía", hacía aparecer a ésta como un verdadero peligro para el poder burgués. Tal situación arrancó al liberalismo un cambio en el sentido de fortalecimiento del Estado, de intervencionismo o garantía de derechos a los ciudadanos, se pasa de la concepción del Estado garante -de la individualidad- a la del Estado gerente. Ahora bien, "el Estado burgués no sólo reforzó su presencia en la economía, sino que el liberalismo legitimó su intrusión en la propia esfera de lo civil, para que regulara los espacios de asociatividad de forma tal que lograra impedir o limitar la constitución de entes colectivos capaces de desafiar el dominio del

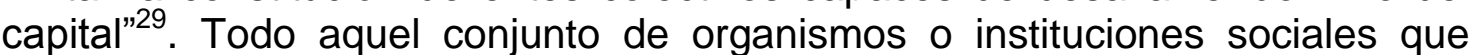
hasta el momento eran considerados como privados (escuela, universidad, asociaciones culturales, etc.) pasan ahora a ser públicas, del Estado politización de la Sociedad Civil-. Gramsci señala: "además de la escuela en sus diversos grados (...) se debe hacer una lista de las instituciones que han de considerarse de utilidad para la instrucción y la cultura públicas y que, como tales se consideran, de hecho, en una serie de Estados; estas instituciones no serían accesibles al gran público -y es evidente que por razones nacionales han de ser accesibles- sin una intervención estatal"30.

"Surgieron las formas modernas de dominación, basadas en lo que puede denominarse expansión molecular del Estado, en un redimensionamiento de su morfología. El Estado capitalista se reestructuró por medio de un proceso que asimiló el desarrollo complejo de la Sociedad Civil a la estructura general de la dominación -la politización de lo social implicó la socialización de la política-" 31 . El sujeto ya no es considerado al nivel de sus actos, sino de sus virtualidades, se entra en lo que Michel Foucault, en Vigilar y castigar (1975), partiendo de la teoría del "panoptismo", de la "sociedad panóptica", de Jeremy Bentham, llamó la época de la ortopedia social o sociedad disciplinaria ${ }^{32}$. Se trata de una forma de poder basada en la conversión de los diferentes espacios de lo civil en productores de reglas capaces de "pre-encauzar" las conductas de los individuos hacia lo considerado "socialmente bueno" por las clases dominantes. Una organización social a partir y en el espacio de la cual emergen determinados tipos de saber y conocimientos que reproducen la dominación.

Sociedad Civil y Sociedad Política pues, se fusionan, este giro influye en la creación de una nueva concepción de Sociedad Civil, la de ésta como "contenido ético de Estado".

\footnotetext{
${ }^{29}$ ACANDA, J.L. Sociedad Civil y Hegemonía. Ob. Cit. Pág. 237.

${ }^{30}$ GRAMSCI, A. Cultura y literatura. Ed. Península. Barcelona. 1972. Pág. 82-83.

${ }^{31}$ Idem. Pág. 241.

${ }^{32}$ Véase FOUCAULT, M. Vigilar y castigar. Ob. Cit. Pág. 199-232.
} 


\section{Los intelectuales y la organización de la hegemonía}

Si al analizar su lugar de constitución hemos podido acercarnos al funcionamiento de la Hegemonía, nos falta, para acabar de comprender este funcionamiento, examinar de que manera se realiza su organización y quienes son los agentes encargados de llevarla a cabo. En Gramsci, ésta corre a cargo de los intelectuales en tanto que categoría social. Conjuntamente con el de Sociedad Civil, el concepto de intelectual ha sido considerado como uno de los conceptos clave de la teoría gramsciana de la Hegemonía. Pero, ¿Qué son para Gramsci los intelectuales?.

La importancia del concepto viene dada, en su misma definición, por el hecho de que ésta no toma como punto de partida: ni, 1) la tradicional distinción entre trabajo manual y intelectual. El criterio que permite distinguir la actividad de los intelectuales de las restantes actividades de los otros grupos, no puede -dice Gramsci- buscarse en las características intrínsecas de dicha actividad, dado que " en cualquier trabajo físico, incluso el más mecánico y degradado, existe un mínimo de calificación técnica, es decir, un mínimo de actividad intelectual creadora (...), la intervención intelectual no puede excluirse de ninguna actividad humana, el homo faver no se puede separar del homo sapiens",33.34; ni, 2) la visión común, de carácter idealista, que concibe a los intelectuales como un grupo que existe por encima y por fuera de las relaciones de producción, esto es, como una elite que monopoliza las distintas formas culturales de conocimiento, creación y expresión. Al contrario, Gramsci habla de una profunda inserción de este grupo en la producción y reproducción del modo de producción;

Frente a estas concepciones, Gramsci plantea un nuevo criterio de diferenciación, lo que permite distinguir los intelectuales de los otros grupos, no es la actividad en si misma que realizan sino la "función" que dentro del sistema de relaciones sociales dicha actividad ejerce. Por intelectuales ha de entenderse todos aquellos que mediante su actividad transmiten valores,

\footnotetext{
${ }^{33}$ GRAMSCI, A. Cultura y Literatura. Ed. Península. Barcelona. 1972. Pág. 31.

34 De acuerdo con esta distinción, el marxismo oficial interpretaba la intelectualidad exclusivamente desde un punto de vista economicista, teniendo en cuenta sólo su tipo de actividad laboral y su relación de propiedad con los medios de producción, y la presentada como un sector o grupo intermedio y ambivalente, que oscilaba entre la burguesía y la clase obrera. Explotada por la primera, se inclina a alinearse con el proletariado, pero condenada al individualismo por las propias características del trabajo que realiza, era considerada como portadora de vicios e inclinaciones pequeñoburguesas; Además, esta concepción concluía con una diferenciación entre intelectualidad científico-técnica, responsabilizada de con el desarrollo de las fuerzas productivas -y, por ende, muy importante para la construcción de un socialismo que se entendía desde una visión cosificada, y que supuestamente realiza una actividad $s$ contenido ideológico-, y la intelectualidad humanista, que no contribuye al desarrollo de las fuerzas productivas, por lo que es menos importante que los ingenieros o los químicos y que, para justificar su existencia en el socialismo, debían devenir propagandistas de la línea del partido, reflejar en sus poemas, pinturas, novelas o esculturas los ideales del realismo socialista y apoyar las directivas del Partido con sus investigaciones y monografías. (ACANDA, J.L. El malestar de los intelectuales. En Revista TEMAS. No. 29. La Habana. Abril-junio 2002. pág. 12).
} 
racionalidades, modos de vida, principios de organización del espacio, modos de actividad, etc. contributivos a la reafirmación o reproducción de las normas de la cultura cotidiana legitimadora de las relaciones sociales (muchas veces incluso de manera inconsciente e independientemente de su voluntad, pues en ocasiones la legitimación viene determinada no por los mismos intelectuales sino por las estructuras des de las que actúan, como puede ser el caso de los miembros de un parlamento o de los partidos políticos) o a la subversión de las mismas. En tanto el poder se estructura, existe y se ejerce, como hemos dicho, en todos los actos o normas del sistema de relaciones sociales o de la cotidianidad -el capitalismo se perpetua gracias al desempeño de poderes que se ejercen por todo el cuerpo social, decía Foucault- y la hegemonía de la clase dominante se enraíza en ellos, los intelectuales que de acuerdo con esta concepción son ahora un fenómeno de masa ("intelectual masa") -hay miles, ya no son unos pocos, los profesores, los locutores de radio y televisión, los artistas, los policías, los militares, los cineastas, etc.- serán los encargados del funcionamiento del aparato hegemónico -Gramsci les llama "intelectuales orgánicos", en tanto son parte orgánica del proceso de reproducción del sistema de relaciones sociales o de la cultura dominante- o de la construcción de espacios contrahegemónicos. "El modo de ser del nuevo intelectual -escribe el autor italiano- ya no puede consistir en la elocuencia motora, exterior y momentánea, de los afectos y de las pasiones, sino que el intelectual a aparece insertado activamente en la vida práctica, como constructor, organizador, persuasivo permanente, no como simple orador"35.

Así pues, esta concepción gramsciana de la intelectualidad tiene mucho que ver con su interpretación de la Hegemonía. Los intelectuales son los agentes sociales de afianzamiento u organización de la Hegemonía.

\section{Disolución de la hegemonía. La crisis orgánica como crisis hegemónica}

En palabras de Gramsci, una de las condiciones para la disolución del sistema hegemónico de la clase dominante es que se produzca una crisis orgánica, que no es más que una ruptura del nexo orgánico entre infraestructura económica y superestructura político-ideológica, esto es, una "crisis de autoridad" de la clase dirigente, una pérdida de su capacidad de control-dirección moral e intelectual 0 , lo que es lo mismo, del consenso: "una crisis orgánica es la ruptura del nexo orgánico entre infraestructura y superestructura, con lo cual el bloque histórico comienza a disgregarse. Una ruptura de tal índole supone que las orientaciones dadas por la clase dominante ya no encuentran justificación ideológica frente a otras clases" ${ }^{36}$. "Si la clase dominante ha perdido el consenso, ya no es dirigente sino únicamente dominante, detentadora de la

${ }^{35}$ GRAMSCI, A. Los intelectuales y la organización de la cultura. Ed. Lautaro. Buenos Aires. 1960. Pág. 15.

${ }^{36}$ GRAMSCI, A. Notas sobre Maquiavelo, sobre la política y sobre el Estado moderno. Ed. Nueva Visión. Buenos Aires. 1972. Pág. 62. 
fuerza coercitiva, esto significa que las grandes masas se han separado de la ideología tradicional, ya no creen en lo que antes creyeron" ${ }^{\text {"37 }}$.

La pregunta que surge aquí será entonces, ¿Por qué la clase dirigente ya no obtiene el consenso?. Ésta deja de tenerlo cuando pierde el control de la producción cultural, cuando ya no puede hacer aparecer sus intereses como intereses generales, esto es, cuando la sociedad civil ya no actúa como espacio de socialización o sujeción sino como espació de rebelión, cuando aparecen en el si de la sociedad civil, en sus distintas instituciones sociales, proyectos concretos de organización-funcionamiento económico, participativo, etc. de tipo contra-hegemónico (con una dinámica interna y leyes de funcionamiento, finalidades, etc. transformada) que, al estar en contacto directo con el empleo del tiempo cotidiano, dispensando una normatividad-disciplina fruto de sus propios códigos autorreguladores, se integran de manera absolutamente anónima en la cotidianidad de los individuos y, por tanto, desarrollan y expanden en ellos lógicas, racionalidades, dinámicas sociales o reglas de civilidad específicas contradictorias con el orden socio-económico formal. La expansión y desarrollo progresivo de proyectos micro de este tipo tiene como consecuencia a largo plazo que, al confundirse y determinar la actividad práctica de los individuos en su interior y por lo tanto, prolongarse también después, transversalmente al conjunto de las relaciones sociales, crearía en la sociedad una situación de conflicto entre ordenes culturalnormativos, donde el orden económico, político y social formal no realizaría las aspiraciones sociales. ${ }^{38} \mathrm{La}$ disolución del bloque histórico sienta en consecuencia, la posibilidad de un nuevo bloque que va constituyéndose entorno a una hegemonía opuesta a la hegemonía que entra en crisis. La hegemonía de la clase dominante sólo puede destruirse si se instaura un nuevo modo de producción social, que permita una apropiación desajenante de la realidad. Es en este sentido que Gramsci afirma que la construcción de una nueva hegemonía liberadora implica la realización de una reforma ${ }^{39}$ intelectual

${ }^{37}$ GRAMSCI, A. Passato e presente. Editori Reuniti. Roma. 1971. Pág. 62.

${ }^{38}$ John Lewis Gillin en su obra Introduction to Sociology (1942), describe este momento de desajustes entre los varios elementos en la configuración total de la cultura que interfiere seriamente en el mantenimiento del consenso, como una situación de patología social. Ahora bien, cuando el desorden que se produce es de tipo constructivo, aquel en que la ruptura de las normas establecidas se produce con el ideal o finalidad, no de crear el desorden puro, el desorden por el desorden, sino para instaurar normas nuevas y reformar instituciones inadecuadas, nada hay de patológico en semejante proceso, por el contrario, es una manifestación de vitalidad, de vida social dinámica. A este tipo de transformación social es a lo que, propiamente y sin tergiversaciones, llamamos "revolución". (Véase GILLIN, J.L. Introduction to Sociology. New York. 1942. Citado por BUSTAMANTE, A.S. Sociología Jurídica. Ed. Facultad de Derecho. Departamento de publicaciones Universidad de La Habana. T.II. La Habana. 1942. Pág. 44-47).

39 "No es casual que Gramsci utilizara en los Cuadernos el concepto de reforma cultural en vez de el de revolución cultural, mas común en el vocabulario marxista. Esto está relacionado con la valoración que hizo de la Reforma religiosa del siglo XVI en Europa (véase la obra de M. Weber citada anteriormente: La ética protestante y el espíritu del capitalismo), en contraposición al Renacimiento. La Reforma devino paradigma en su representación del cambio social, pues encarnaba un modelo de lo que significaba el desarrollo de una nueva hegemonía cultural. Gramsci estableció una comparación entre el Renacimiento y la Reforma; 
y moral que sea capaz de crear una nueva cosmovisión e ideología en el pueblo.

Esta es una concepción que se diferencia de la visión economicista, mecanicista y estrechamente estatalista y juridicista de los procesos de transición hacia una sociedad anticapitalista defendida por el marxismo dogmático. La subversión de la sociedad capitalista era entendida por este último, simplemente como la toma del control estatal y la eliminación de la propiedad privada mediante un acto de violencia ejercido por el nuevo Estado, por medio de la formulación y ejecución de instrumentos jurídicos creados al efecto. La tesis gramsciana concibe la revolución no como un simple golpe de fuerza sino como un proceso. La toma del poder por la fuerza era necesario, según Gramsci, pero como eslabón último de la implantación del nuevo poder, previamente hacía falta llevar a cabo una revolución en la esfera gnoseológica. El dominio de una clase sobre la economía y la política no puede sostenerse, sólo que por la coacción, sino hay también, a priori, una apropiación por parte de esta clase de los paradigmas racional-subjetivos generales legitimadores del modelo social, la emancipación político-económica de las clases populares es imposible sin su emancipación cultural.

De ahí que el autor de los Cuadernos usando el vocabulario militar, común en sus escritos, se refiera a la "guerra de posición" -en tanto contrario de la "guerra de maniobras"- como el tipo peculiar de ataque sobre la sociedad capitalista para construir un proyecto hegemónico. En el caso de las sociedades de capitalismo avanzado, a las que él denomina "Occidente", su hegemonía se basa en la dirección intelectual y moral de la sociedad, en la impregnación ideológica de todo el sistema social, por eso, el asalto del poder solo puede triunfar si hay primero un proceso de disgregación de la sociedad civil como instrumento de sujeción para convertirla en instrumento de socialización de la rebelión, la revolución debe entenderse en primer lugar como un "hecho filosófico", como un "acto pedagógico" capaz de dotar a las masas de un pensamiento crítico que logre liberarse de los dogmas y mitos recurrentes en el sentido común, las revoluciones centro-europeas de 1919-1921 fracasaron por que no hubo este proceso previo, establece el autor sardo. La situación es radicalmente diferente en otros países, en terminología de los Cuadernos de "Oriente", donde, debido a la incompleta difusión de las relaciones capitalistas, la sociedad civil es "primitiva y gelatinosa" 40 , siendo posible construir un sistema hegemónico directamente mediante un asalto violento del poder o "guerra de maniobra". Como establece Gramsci: "me parece que llici -se refiere a Lenin- había comprendido que se necesitaba un cambio de guerra de

el primero origino el surgimiento de grandes intelectuales, pero no provocó transformación efectiva alguna en la cultura popular. La Reforma, por el contrario, significó un cambio cultural profundo y radical, que se expresó en la transformación de los modos de vida, los valores y las concepciones de los estratos intelectuales inferiores, de los simples. De la misma manera, la construcción de la hegemonía liberadora significa un cambio tan radical como aquel ". (ACANDA, J.L. Sociedad Civil y Hegemonía. Ob. Cit. Pág. 297-298).

${ }^{40}$ GRAMSCI, A. Notas sobre Maquiavelo, sobre la política y sobre el Estado moderno. Ob. Cit. Pág. 95. 
maniobra, aplicada victoriosamente en Oriente en el 17, a la guerra de posición que era la único posible en Occidente" ${ }^{41}$.

\section{Conclusiones}

Hasta aquí he realizado una aproximación a la teoría gramsciana. Su estudio nos da la base para poder realizar las siguientes conclusiones que nos permiten refrendar la tesis afirmada al inicio:

- Entendemos por cultura la unión de una concepción del mundo (cosmovisión) con una forma de organización social y unas normas de conducta que se desprenden de ella.

- La identidad es la conciencia de compartir una serie de rasgos o características, lo que implica formar alguna especie de comunidad, y que estos rasgos son lo que diferencian al grupo frente a "los otros".

- Una clase social hegemónica consigue crear un modelo de dominación de carácter consensualista porque es capaz de estructurar la construcción ideológica de la sociedad alrededor de un sistema cultural. La Hegemonía una producción cultural.

- A la vez, los hechos de cultura son susceptibles de actuar como hechos de identidad (auto-conciencia de la propia cultura), pudiéndose plasmar su incremento en el diseño de proyectos sociales y en la elaboración de ideología -se convierte en identidad política- (componente cognoscitivo o "reflexivo" de la identidad) que activan en los individuos una potencial capacidad de replantearse la sociedad "dada" -naturalizada(dominación/hegemonía) para dar paso a la construcción de nuevas "comunidades" (liberación/contra-hegemonía).

- Concominante con el desarrollo de la mundialización capitalista se ha producido una decapitación teórica del concepto de cultura. Se impone una noción esencialista de la cultura (ajena a las cambiantes condiciones de vida -"ente externo" convertido en variable independiente-), y consecuente con ello, su aprensión como de si una cosa se tratara (cosificación).

- Al separarse la cultura de las relaciones materiales de los hombres, del proceso social en curso. La vinculación de la identidad con esas relaciones se pierden en la conciencia, dando paso a formas generalizadas de alienación con respecto a la propia cultura cotidiana (la que se vive y genera cada día), y con ella, la hegemonización de un nuevo sistema cultural de relaciones sociales externo (mercantilizado) y la pérdida de la capacidad de las poblaciones de "decidir" o identificar su cultura-identidad, que es tanto como decir, su realidad ${ }^{42}$ (surgimiento de una ciudadanía liberal acríticamente asumida).

\footnotetext{
${ }^{41}$ GRAMSCI, A. Quaderni del carcere. Einaudi. Turín. Pág. 866. (Citado por ACANDA, J.L. Sociedad Civil y Hegemonía. Ob. Cit. Pág. 283-284).

${ }^{42}$ Sobre ello véase HOLLOWAY, J. Change the World Without Taking Power. Pluto Press. Sterling. 2002; y, PIQUERAS, A. La identidad. En DE LA CRUZ, I. (coord.) Introducción a la antropología para la intervención social. Ob. Cit.
} 
- La recuperación y revisión de todo el legado teórico de Gramsci aquí explicado permite, y es fundamental en la actualidad, para la reconstrucción o el "rearme" de un concepto ampliado o "completo" de cultura que nos permita comprender las formas modernas de dominación, consiguiendo una "socialización de la reflexibilidad" que lleve a emprender en las distintas comunidades re-elaboraciones culturales e identitarias tendentes a desorganizar las relaciones y posiciones sociales dominantes y no propias.

En consecuencia, no cabe duda, tal como afirmaba al inicio del artículo, que la obra de Gramsci se constituye como un instrumento teórico fundamental en la actualidad para enfrentar eficazmente los problemas complejos y urgentes de la dominación y la liberación. 